https://doi.org/10.36396/MS.2019.14.03.007

\section{Влиянние кратковременных физических упражнений на гемодинамический аспект функщии эндотелия плечевой артерии человека}

А.М. МЕАЬКУМЯНЬ, Т.В. БАЛАХОНОВА, О.А. ПОГОРЕАОВА, М.И. ТРИПОТЕНЬ

ФГБУ НмИЦ карАиологии Минздрава РФ, Москва, Россия

В экспериментах на 10 мужиинах-ообровоььиах в возрасте 50-60 лет без выраженной сердечно-сосудистой патооогии исследовали вмияние относительно кратковременных (по 30-50 мин. в Аень) физических упражнений, сопряженных с повышением напряжения сввига в ПА, на величину эндотелий-зависимой вазодиматтаиии этой артерии, вызываемой увеличением в ней скорости кровотока. В контрольном периоде на обеих руках испытуемых регистрировали эньотелий-зависимую Аиматаиию ПА, вызываемую увеличением кровотока в период реактивной гиперемии, скедуюшей за оккююзией, Аиттельностью 5 мин. После 4 Аней, в течение которых кажый испытуемый периовически увеличива кровоток в сосудах тољько левой руки, ритмически сжимая ею в течение 30-50 мин. в сутки резиновый кистевой эспанцер, вновь измеряли

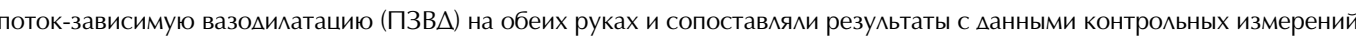

В контрольных измерениях реакции ПА обеих рук на повышение кровотока, вызванного оккиюзией, были практически одинаковы (4,98 + 0,3\%

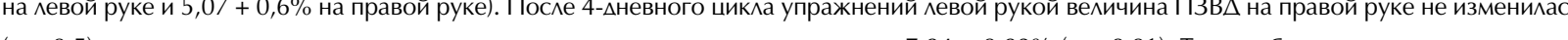

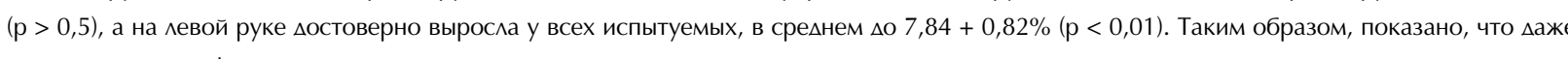
кратковременные физические упражнения, сопряженные с увеличением деиствуюшего на стенку артерии напряжения сАвига, заметно улуч шают способность эндотелия рассаабяять сосуцистые глаАкие мышыы при увеличении кровотока. Этот результат подтвержАает преАставление о том, что трансформация эндотемиального гликокаликса под действием напряжения сввига улучшает механоцептивную функцию энцотелия.

Кнючевые слова: эндотемий-зависимая вазодиматаиия, гликокаиикс, напряжение сАвига, кровоток.

Effect of short-term physical training on hemodynam-ic aspects of endothelia function in human brachial artery

A.M. MELKUMYANTS, T.V. BALAKHONOVA, O.A. POGORELOVA, M.I. TRIPOTEN

National Cardiology Research Center, Moscow, Russia

In experiments on 10 volunters (men aging 50-60 years without cardiovascular diseases), the study examined the effect of relatively short (30-50 minutes daily) physical training, which increased the wall shear stress in brachial artery (BA), on endothelial-dependent tlow-induced dilation (FID) of BA. In the control period, FID caused by an increase of blood flow resulting from a 5-min occlusion was measured in left and right BA. In the following 4 days, the examinees periodically increased blood flow in left BA by rhythmic compressions of a rubber carpal expander during 30-50 min daily. After this training session, FID was measured in both BA and compared with the data obtained during the control trials. In the control period, FID in both BA were practically identical ( $4.98+0.3 \%$ in left BA vs $5.07+0.6 \%$ in right BA). After a 4 -day-long training, the dilator response of left BA significantly increased to $7.84+0.82 \%$ $(p<0.01)$, while the response of right BA remained virtually unchanged $(p>0.5)$. The data demonstrate that even a short-erm physical training, whic increased the wall shear stress, improves the ability of arterial endothelium to relax smooth muscle in response to an increment of the blood flow. The data suggest that transformation of endothelial glycocalyx caused by an increase in shear stress improves the mechanoceptive endothelial function.

Key words: endothelial-dependent dilation, glycocalyx, shear stress, blood flow.

\section{Сведения об авторах:}

МИЦ карциологии $\mathrm{M} 3 \mathrm{PФ}$, А. б. н. профессор, e-mail: artmelk@gmail.com, тел. 8 (903) 518-84-21, https//:orcid.org/0000-0003-2948-5382. Бамахонова Татьяна Ваментиновна - ГА. научный сотруАник отАела ультразвуковых методов исссееования Института қ

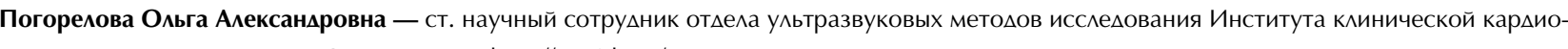

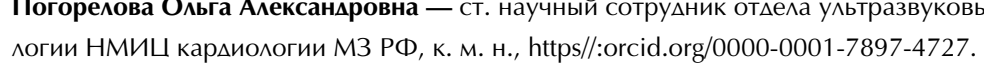

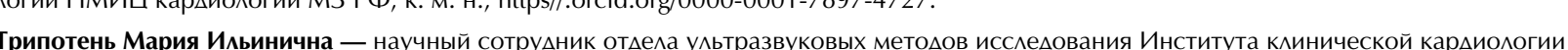
НМИЦ кардиологии МЗ РФ, К. М. н., https//:orcid.org/0000-0003-4462-3894.

\section{О Комлектив авторов}

Атеросклероз, являющийся основной причиной многих заболеваний сердечно-сосудистой системы, на начальных заболеваний сердечно-сосудистой системы, на начальных этапах разини определяесся нарушением нормального функционирования эндолелия. Данные патологоанатомических исследованй сосудов человска и результаты экспе риментов, проведенных на животных, показывают, что первые признаки атеросклеротического поражения сосудов, выражающиеся в виде локализующихся в субэндотелии жировых полосок, проявляются в тех участках артерий, для которых характерно низкое напряжение сдвига [1]. В этих же участках впоследствии наблюдаются атероматозные бл

ки, обуславливающие стеноз артериальных сосудов

Исследования последних двух десятилетий показали, что дисфункции эндотелия предшествует повреждение гликокаликса - слоя макромолекул, обращенных в просве сосуда и производимых эндотелиоцитами. Это «покрытие эндотелиальных клеток, по структуре напоминающее кустарник, состоит из заякоренных в плазмалемме гликозаминогликанов, протеогликанов, гликопротеинов и гликолипидов [2]. Истончение гликокаликса приводит к увеличению проницаемости сосудистой стенки и быстрому прогрессированию атеросклеротического процесса [3].

Толщина и состав эндотелиального гликокаликса зависят от величины действующей на сосудистую стенку со стороны текущей крови силы вязкого трения - напряжения сдвига. Основанием для такого утверждения являются, во-первых, данные, свидетельствующие о том, что в участках сосудистого русла, для которых характерно низкое напряжение сдвига, толщина гликокаликса значительно уменьшена, именно в этих областях развиваются атеросклеротические поражения [4, 5]. Во-вторых, результаты этих же работ свидетельствуют о том, что чем выше действующее на стенку напряжение сдвига, тем толще слой эндотелиального гликокаликса, препятствующего проникновению в стенку частиц липопротеидов, несущих холестерин. В этих областях атеросклеротическое поражение никогда не наблюдается.

T. Arisaka и соавт. [6] и М. Gouvernier и соавт. [7] в опытах на культуре эндотелиальных клеток свиней и человека показали, что повышение напряжения сдвига стимулирует увеличение концентрации в гликокаликсе гликозаминогликанов, в частности содержания гиалуронана. Эти данные позволяют предполагать, чте происходящее во время физических упражнений повышение напряжения сдвига на стенке артерий, приводяшее к утолшению гликокаликса, должно улучшат функцию эндотелия и тормозить развитие атеросклеротического прошесса

В течение двух последних десятилетий в ряде теоретических и экспериментальных работ [8-10] показано, что именно волокна гликокаликса являются механорецепторами, воспринимаюшими действуюшее на стенку напряжение слвига и, таким образом, опреде сенке величину дилататорной реакнии сосудов на повьщим кровотока [11]. Задача настояшего исследования сокровотока [11]. Зада асыл как влияют физические пражнения, сопряженные с относительно краткоре- менным увеличением напряжения сдвига в артериях руки человека при рабочей гиперемии, на величину

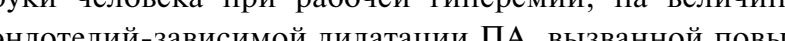
шением в ней кровотока, происхо вим в хой посокклор стрит во обеих руках испытуй в контрольом

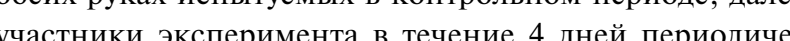
ски у вел эк в руки в 4-дневных упражнений вновь регистрировали величину ПзВД на обеих руках.

\section{Методы исследования}

В экспериментах участвовали 10 мужчин-добровольцев в возрасте от 50 до 60 лет, не имеющих выраженно сердечно-сосудистой патологии. Все участники дали информированное согласие на участие в исследовании, а сами эксперименты проводили в полном соответствии с Хельсинкской декларацией 1975 года и ее пересмотренным вариантом 2000 года.

Все участники исследования были правши. Из них 9 испытуемых - нормотоники (артериальное давление (АД) в покое - не выше 120/80 мм рт. ст.); 1 испытуемый гипертоник с фармакологически (хинаприл, 10 мг/сут.) компенсированным АД (в пределах 120/80 мм рт. ст.) У 9 испытуемых уровень общего холестерина был нормальным (< 4,8 ммоль/л), у 1 испытуемого (у того, который принимал гипотензивный препарат) общий холестерин был несколько повышен (6,2 ммоль/л). Индекс массы тела испытуемых составлял 27,81 +3,48 кг/м².

Протокол исследования. В контрольном периоде каждого эксперимента у испытуемого на обеих руках регистрировали ПЗВД, вызываемую увеличением кровотока в период реактивной гиперемии, развивающейся в результат окклюзии ПА длительностью 5 мин. Далее в течение 4 днеи каждый испытуемый периодически увеличивал кровоток в сосудах левой руки в ходе рабочей гиперемии, которая достигалась ритмическим сжатием резинового кистевого эспандера. Общее время, в течение которого ежедневно производились такие физические упражнения, составляло 30-50 мин. Каждый цикл упражнения длился 60-90 c. продолжать сжатие эспандера непрерывно более 90 с. было практически невозможно из-за развития утомления мыши предплечья и появления болевой реакции. Таким образом, ежедневно каждый испытуемый производил 40-60 циклов работы левой рукой длительностью 60-90 с. каждый. Через 4 суток после контрольного измерения у всех испытуемых вновь измеряли ПзВД на обеих руках.

Для того чтобы оценить, насколько увеличивается напряжение сдвига в ПА в ходе рабочей гиперемии, у 3 испытуемых в контрольном периоде измеряли изменения объемной скорости кровотока и диаметра ПА вызываем объемной скорости кровотока и диаметра ПА, вызываемые

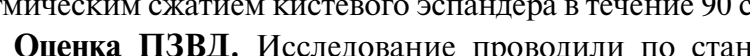
с использованием ультразву- 
ковой системы Philips IU22 (США) с линейным датчиком 3-9 МГц. После 10-минутного отдыха в положении пациента лежа на спине измеряли АД по методу Короткова Далее ПА сканировали в продольном сечении в В-режиме ультразыукового сканирования на протяжении $3-5 \mathrm{~cm}$ выше локтевого спба. Глубину и усиление ультразвукового сигнала подбирали для получения оптимального изображения артерии с наилучей визуализацией границы раздела «интима-просвет сосуда» передней и задней стенок, и данные параметры оставались неизменными на протяжении всего исследования. Во время получения изображения ПА фиксировали анатомические ориентиры, такие как вены или связки, для регистрации одного и того же сегмента в ходе всего исследования. После установления места измерения определяли диаметр ПА в состояние покоя. Далее на предплечье, дистально от места сканирования артерии, накладывали манжету сфигмоманометра, в которую нагнетали воздух до давления на 30-50 мм рт. ст. выше систолического АД, создавая артериальную окКлюзию. Спустя 5 мин. проводили декомпрессию манжеты, что приводило к развитию постокклюзионной гиперемии (повышению кровотока в ПА) После декомпрессии манжеты продольное изображение ПА регистрировали непрерывно на протяжении $90 \mathrm{c}$ В течение всего исследования изображение ПА было синхронизировано с R-зубцом ЭКГ; все измерения диаметр ровали в базу данных рабочей станции MultiVox. Диамет зии, далее через 60 и $90 \mathrm{c}$. после декомпрессии манжеть. Величину ПЗВД ПА вычисляли по формуле:

ПЗВД = [(Дрг - Дисх) $/$ Дисх] 100\%, где Дрг - максимальный диаметр ПА, который обычно достигался через 60 с. после декомпрессии манжеты, Дисх - исходный диаметр ПА.

Кровоток в ПА во время рабочей гиперемии (измерявшийся у 3 испытуемых) определяли с помощь

Статистика. Данные измерений представлены в виде $\mathrm{m}+\mathrm{SD}$. Достоверность различий в парах измерений устанавливали с помощью непараметрического теста Краскела - Уоллиса. Достоверным считали различие при р $<0,05$.

\section{Результаты исследования}

В контрольном периоде диаметры ПА правой и левой рук достоверно не различались $(4,02+0,43$ и $3,97+0,32$ мм соответственно; $\mathrm{p}>0,2, \mathrm{n}=10$ ). Также статистически незначимо было различие ПзВД на обеих руках $(4,98+0,3 \%$ на левой руке и $5,07+0,6 \%$ на правой руке, $\mathrm{p}>0,1$,
см. рис. 1). Артериальное давление у всех испытуемых вм. рис. 1). Артериальное давление у всех испытуемых 125/85 мм рт. ст.

У 3 испытуемых, у которых оценивали увеличение напряжения сдвига в ПА в ходе рабочей гиперемии, через 90 с. после начала физического упражнения кровоток влевой ПА увеличивался на $67-82 \%$ по сравнению с конв

при этом возрастал на 3,8-4,6\%. Учитывая, что при ла-

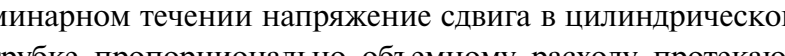

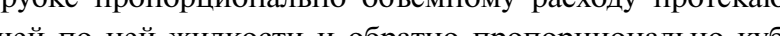
жей по ней жидкости и обратно пропорционально кубу ее диамегра, оценивали слепень увеличения напряжения

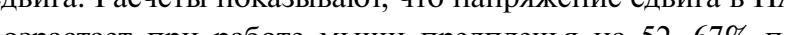
возрастает при работе мышц предплечья на 52-67\% по сравнению с состоянием покоя: если в состоянии покоя расчине зачение напряжения сдвига составляет примерно 10-11 дин $/ \mathrm{cm}^{2}$, то при ритмическом сжатии эспандера в в-чение 0 с. напряжение сдвига достигает величины $15-18$ дин/см . Таким образом, в каждом цикле работы (длительностью $60-90$ с.) напряжение сдвига на стенке ПА

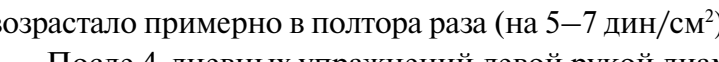

После 4-дневных упражнений левой рукой диаметрь ббеих ПА в состоянии покоя достоверно не отличались о данных контрольных измерений $(\mathrm{p}>0,1)$. Однако ПЗВД плечевой артерии рабочей (левой) руки у всех испытуемых значительно увеличивалась по сравнению с контрольной величиной. В среднем величина ПзВД после упражнений составляла $7,84+0,82 \%$ против $4,98+0,30 \%$ в контроле $(\boldsymbol{p}<0,01)$. В то же время величина ПЗВД плеевой артерии правой руки оставалась практически тако же, как в контроле $(5,12+0,71 \%$ против $5,07+0,68 \%)$, Данные этих экспериментов представлены на рисунке 1. Расчет, проведенный по закону Пуазейля (сопротивление сосуда обратно пропорционально четвертой степени ее диаметра), показывает, что при контрольных измерения максимальне уменьшение тидравлического сопротивления левой ПА в ходе постокклюзионной гиперемии составляло $18,1+0,4 \%$, а после 4-дневных физических упражнений максималн, ае уменьпение сопротивления этого сосуд составляло $27,8+1,9 \%$. Важно отметить отсутствие значимого различия величины максимального кровотока, достигавшегося в ходе постокклюзионной гиперемии, до и после 4-дневных физических упражнений ( $>$ > 0.2).

\section{Обсужиение}

Физическая активность считается одним из самых распространенных и наиболее рекоменлуемых способо профилактики сердечно-сосудистой патологии. Обычно положительный эффект физической активности связывают с улучшением липидного спектра крови: снижением

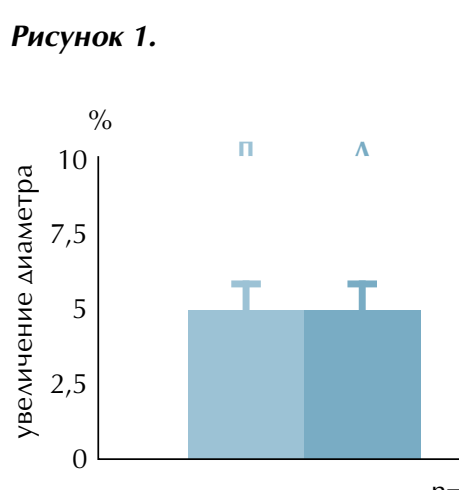

$n=10$

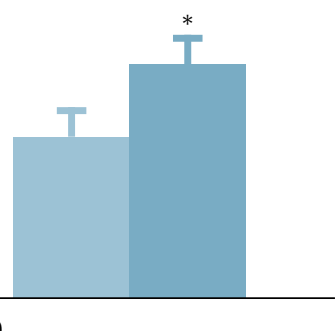

КАРДИОЛОГИЧЕСКИЙ ВЕСТНИК, 3, 2019 уровня общего холестерина и его атерогенных фракций холестерина липопротеидов низкой плотности, триглицеридов, а также новышением концентрации антиатерогенного холестерина липопротеидов высокой плотности $[14,15]$. Полагают, что эти факторы улучшают состояние и функцию сосудистого эндотелия, что снижает риск развития заболеваний, обусловленных атеросклерозом и дисфункцей эндогелия. Основными видами рекомендуемых физических упражнений является ходьба (минимум 30 мин. в день 5 дней в неделю) и тренировка на кардиотренажерах в течение такого же времени. Поскольку такие упражнения сопровождаются увеличением минутного объема кровообращения и повышением кровотока в артериях большинства скелетных мышц и в коронарных сосудах, естественно ожидать улучшения эндотелиальной функции всех артерий, т. е. некоего генерализованного эндтелий-протективного эффекта.

В проведенном же нами исследовании физическое упражнение было локальным: оно ограничивалось работой мышц предплечья одной руки и, соответственно, увеличением кровотока только в сосудах этой работающе конечности. Эффект, наблюдающийся при таком воздействии, не может быть связан с системными изменениям липидного обмена, а отражает влияние на механочувствительность эндотелия только изменений местной гемодинамики. Об этом свидетельствует отсутствие изменений ПЗВД в ПА неработавшей руки. Таким образом, полученные в этой работе данные демонстрируют положительный эффект чисто механического воздействия (кратковременного увеличения напряжения сдвига) н функцию эндотелия, исключая возможное положительное влияние улучшения липидного спектр.

Поскольку рецепторным звеном дилататорной реакции артерий, вызываемой увеличением кровотока, является эндотелиальный гликокаликс [8-11], то правомерно предположить, что наблюдавшийся эффект обусловле именно кратковременной «тренировкой» гликокаликс повышенным напряжением сдвиг

В пользу этой гипотезы свидетельствуют некоторые данные литературы. Во-первых, в работе [16] было показано, что у здоровых молодых мужчин умеренные физические упражнения (по 40 мин. в день 4 раза в неделю) приводили в течение 20 нед. к выраженному уменьшению содержания в плазме крови таких составляюших гликокаликса, как синдекан-1 и гепаран-сульфат, что свидетельствует о том, что физическая нагрузка противодействуе повреждению эндотелиального гликокаликса и обеспечивает сохранение его целостности.

Более важные результаты были получены в исследовании, выполненном Zeng и соавт. [17]. На культуре эндотелиальных клеток было продемонстрировано ремоделирование гликокаликса под действием кратковременного (30 мин.) увеличения напряжения сдвига. В этой работе авторы выяснили, что если в отсутствие механического воздействия на эндотелиоциты гепаран-сульфат (составляюший более $50 \%$ гликозаминогликанов, отвечаюших за механорецепцию эндотелия) покрывает оюминальную поверхность клеток эндотелия практически равномерно,

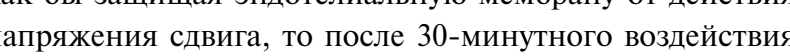
напряжением сдвига, равном 15 дин/ $\mathrm{cm}^{2}$, гепаран-сульфат смещается к границе клетки вниз по потоку, что обпер передачу сдвиговых деформаций от коровых бел. альфа-актина кортикального слоя эндотелиоцитов. Такая трансформация и переориентация волокон тликокаликса долкна улучшать способность клеток эндотелия реагировать на изменения действующего на сосудистую стенку напряжения сдвига, что вполне может сопровождаться усилением диларарного ответа артерий, развивающегося при увеличении в них кровотока. На наш взгляд, именно такой эффект наблюдался в осуществленных нами спериментах.

Регуляция гидравлического сопротивления артерии В соответствии с величиной напряжения сдвига на эндотелии играет важнейшую роль в функционировании сосудистой системы, обеспечивая не только достижение максимального кровотока при рабочей гиперемии, но и противодейссвие констрикции и воспрепятствование развитию сосудистого спазма [18], а также обеспечение острой стадии развития коллатерального кровоснабжения органов при окклюзии магистральных стволов [19]. Поскольку механоцептивным элементом, обеспечивающим реакцию артериальных сосудов на повышение напряжения сдвига, является эндотелиальный гликокаликс и эксперименты показали, что слой молекул гликокаликса тем толще, чем выше действующее на него напряжение сдвига [4-6], то вполне естественно предполагать, что повышение напряжения сдвига на стенке сосудов должно улучшать способность эндотелиоцитов обеспечивать расширение артерий при увеличении скорости кровотока. Такой вывод непосредственно следует из математической модели [20], которая показывает, что чем длиннее молекулы гликокаликса, тем больше их изгибная деформашия под действием одного и того же напряжения сдвига.

Именно гипотеза о том, что повышение напряже ния сдвига способно улучшать механочувствительность эндотелия за счет удлинения волокон гликокаликса, даже кратковредтавленной работе. Мы показали, че сопряженная с увеличением действующего на стенку артерий напряжения сдвига, при регулярном применении заметно улучшает способность эндотелия здоровых испытуемых расслаблять сосудистые гладкие мышцы при увеличении кровотока. Важно, что наблюдаемый нами эффект был однонаправленным: ПЗВД улучшилась у всех без исключения испытуемых, что позволяет полагать, что регулярное механическое воздействие, обуславливаюшес повышение напряжения сдвига на эндотелии, является универсальным механизмом, улучшаюшим механоцептивную функцию эндотелия

Отметим, что полученный результат еще не дает основания делать однозначный вывод о том, что именно рансформация эндотелиального гликокаликса под действием напряжения сдвига, увеличение которого пройхолит во время физических упражнений, улучшает меха- 
ноцептивную функцию эндотелия. Однако такой вывод представляется вполне вероятным, хотя и требует дальнейших экспериментальных подтверждений.

Наконец, отметим два важных обстоятельства. Во-первых, в проведенном нами пилотном исследовании выраженное увеличение эндотелий-зависимой дилатации артерии, вызванной повышением скорости кровотока, наблюдалось после весьма кратковременного (в течение всего 4 дней) воздействия на сосудистую стенку периодическим повышением напряжения сдвига. Вполне резонно полагать, что более длительные физические упражнения будут приводить к более выраженному увеличению дилататорного ответа артерии на повышение кровотока.
Во-вторых, хотя известно, что ПЗВД значительно снижена у больных гипертонической болезнью [13] и даже у молодых пациентов с поражением коронарных артерий [21], мы не пытались выяснить, как влияет (и влияет ли) кратковременное увеличение напряжения сдвига на функцию эндотелия у больных с патологией сердечно-сосудистой системы. Поиск ответа на этот важный вопрос может, по нашему мнению, стать предметом будущих клинических исследований.

Авторы заявляют об отсутствии конфликта интересов. Работа поддержана Российским фондом фундаментальных исследований (грант №16-04-01119).

\section{ЛИТЕРАТУРА/REFERENCES}

1. Caro C., Fitz-Gerald J., Schroter R. Arterial wall shear and distribution of early atheroma in man. Nature. 1969; 223:1159-1161. https://doi. org/10.1038/2231159a0

2. Weinbaum S., Tarbell J.M., Damiano E.R. The structure and function of the endothelial glycocalyx layer. Annu. Rev. Biomed. Eng., 2007, 9:121-167. https://doi:10.1146/annurev.bioeng.9.060906.151959

3. van den Berg B.M., Spaan J.A., Rolf T.M., et al. Atherogenic region and diet diminish glycocalyx dimension and increase intima-to-media ratios at murine carotid artery bifurcation. Am. J. Physiol. 2006; 290:H915-H920. https://doi. org/10.1152/ajpheart.00051.2005

4. Wang S., Okano M., Yoshida Y. Ultrastructure of endothelial cells and lipid deposition on the flow dividers of brachiocephalic and left subclavian arterial bifurcations of the rabbit aorta. J. Japanise Atheroscler. Soc. 1991; 19:1089-1100.

5. Woolf N. The arterial endothelium. In: Crawford ST, ed. Pathology of atherosclerosis. London, Butterworths \& Co Ltd., 1982:25-45.

6. Arisaka T., Mitsumata M., Kawasumi M., et al. Effects of shear stress on glycosaminoglycan synthesis in vascular endothelial cells. Ann NY Acad Sci. 1995; 748:543-54. http://doi.org/10.1111/j.1749-6632.1994. tb17359.x

7. Gouverneur M., van den Berg B., Nieuwdorp M., et al. Vasculoprotective properties of the endothelial glycocalyx: effect of fluid shear stress. J. Intern. Medicine. 2006; 259: 393-400. https://doi.org/10.1111/j.1365-2796.2006

8. Florian J.A., Kosky J.A., Ainslie K., Pang Z., et al. Heparan sulfate proteoglycan is a mechanosensor on endothelial cells. Circulat. Res. 2003; 93:136-142. https://doi.org/ 10.1161/01.res.0000101744.47866.d5

9. Pahakis M.Y., Kosky J.R., Tarbell J.M. The role of endothelial glycocalyx components in mechanotrasduction of fluid shear stress. Biochem Biophys Res Comm. 2007, 355(1):228-233. https://doi:10.1016/j.bbrc.2007.01.137

10. Мелькумянц А.М., Балашов С.А., Гончар И.В. Влияние повреждения эндотелиального гликокаликса на способность артерий регулировать свой просвет при изменениях скорости кровотока. Росс. физиол. ж. им. И.М. Сеченова. 2017; 103:1370-1376. [Melkumyants A., Balashov S., Gonchar I. The influence of the endothelial glycocalyx injury on the ability of arteries to control their lumen by blood flow. Russ. Physiol. J. 2017; 103:13701376. (In Russ.)]

11. Мелькумянц А.М. О роли эндотелиального гликокаликса в механогенной регуляции сопротивления артериальных сосудов. $\boldsymbol{Y}_{\text {cne- }}$ хи физиол. наук. 2012; 43:45-58. [Melkumyants AM. Role of endothelial glycocalyx in mechanogenic control of arterial hydraulic resistance. Uspekhy Physiologicheskikh nauk. 2012; 43:45-58. (In Russ.).

12. Celermajer D.S., Sorensen K.E., Gooch V.M., et al. Non-invasive detection of endothelial dysfunction in children and adults at risk of atherosclerosis. Lancet. 1992; 340: 1111-1115. https://doi.org/10.1016/0140-6736(92)93147-F
13. Иванова О.В., Рогоза А.Н., Балахонова Т.В. и др. Определение чувствительности плечевой артерии к напряжению сдвига на эндотелии как метод оценки состояния эндотелийзависимой вазодилатации с помошью ультразвука высокого разрешения у больных с гипертонической болезнью. Кардиология. 1998, 38(3):37-41. [Ivanova OV, Rogoza AN., Balakhonova TV et al. The determination of the brachial artery sensitivity to the shear stress on endothelium as a method for assessing the state of endothelium-dependent vasodilation using ultrasound of high resolution in patients with arterial hypertension. Kardiologiya. 1998, 38(3):37-41.]

14. Бубнова М.Г., Аронов Д.М., Бойцов С.А. Обеспечение физической активности у граждан, имеющих ограничения в состоянии здоровья. Методи ческие рекомендаиии. Москва. 2015. [Bubnova MG, Aronov DM, Boytsov SA. Provision of physical activity in persons with health problems. Guidelines. Moscow. 2015. (In Russ.).]

15. Бубнова М.Г., Аронов Д.М., Перова Н.В. и др. Физические нагрузки и атеросклероз: влияние динамических нагрузок разной интенсивности на показатели липид-транспортной системы и углеводного обмена у больных коронарной болезнью сердца и сахарным диабетом 2-го типа. Кардиология. 2005; 11:33-40. [Bubnova MG, Aronov DM, Perova NV et al. Physical training and atherosclerosis: influence of dynamic training of different intensity on the data of lipid-transporting system and carbohydrate metabolism in patients with coronary heart disease and diabetes mellitus II. Cardiology. 2005; 11:33-40. (In Russ.).]

16. Majerczak J., Grandys M., Duda K. et al. Moderate-intensity endurance training improves endothelial glycocalyx untegrity in healthy young men. Exp. Physiol. 2017, 102.1:70-85. https://doi:10.1113/EP085887.

17. Zeng Y., Waters M., Andrews A. et al. Fluid shear stress induces the clustering of heparin sulfate via mobility of glypican-1 in lipid rafts. Am. J. Physiol. 2013 305:H811-H820. https://doi.org/10.1152/ajpheart.00764.2012

18. Melkumyants A.M., Balashov S.A., Kartamyshev S.P. Anticonstrictor effect of endothelium sensitivity to shear stress. Pflugers Arch. 1994, 427:264-269.

19. Мелькумянц А.М.., Балашов С.А. Механочувствительность артериального эндотелия. Москва. 2005. С. 205. ISBN 5-94789-133-6. [Melkumyants AM, Balashov SA. Mechanosensitivity of the arterial endothelium. Moscow. 2005. p.205. (In Russ.).]

20. Han Y., Weinbaum S., Spaan J.A.E., Vink H. Large-deformation analysis of the elastic recoil of fibre layers in a Brinkman medium with application to the endothelial glycocalyx. J. Fluid Mech. 2006, 554:217-235. https:// doi:10.1017/S0022112005007779

21. Lieberman E., Gerhard M., Uehata A., et al. Flow-induced vasodilation of the human brachial artery is impaired in patients $<40$ years of age with coronary artery disease. Amer. J. Cardiol. 1996; 78:1210-1214. doi.org/10.1016/S00029149(96)00597-8 